\title{
INDUSTRIAL TWINS AS AN EFFECTIVE TOOL FOR THE IMPLEMENTATION OF LABORATORY CLASSES
}

\author{
Arkadiusz KOLKA ${ }^{1 *}$, Maciej KAŹMIERCZAK ${ }^{2}$ \\ ${ }^{1}$ Silesian University of Technology, Machine Technology Department; arkadiusz.kolka@polsl.pl, \\ ORCID: 0000-0002-5713-4670 \\ ${ }^{2}$ Silesian University of Technology, Machine Technology Department; maciej.kazmierczak@polsl.pl, \\ ORCID: 0000-0003-4382-1602 \\ * Correspondence author
}

Purpose: The main aims of the article is to present a solution to the problem that has arisen in connection with the pandemic and the need for distance teaching of vocational subjects

Design/methodology/approach: The proposed methods of solving the problem are based on the use of digital twins created by integrating existing components by developing hardware and software solutions.

Findings: An effective solution was obtained that allows to improve the availability of workshop resources during remote learning and use them in the educational process. The development of techniques combining the virtual and real world seems to be a necessity. The developed solution is a step towards modernizing the approach to the teaching process in the discussed area.

Practical implications: The technical university will have to develop the availability of techniques integrating virtual reality and the real world, which results from the solutions imposed by the development of Industry 4.0. The creation of digital twins for most laboratory equipment will be necessary.

Social implications: Working in a hybrid mode with the use of digital twins in the case of student groups allows for effective development of awareness of responsibility in team work.

Originality/value: An effective methodology for teaching the operation of advanced machine tools was implemented. Tools of this type are new solutions in the field of education, necessary from the point of view of education for employees of the future industry.

Keywords: pandemic time, remote education, virtual reality, digital twins, industry 4.0.

Category of the paper: Technical paper, General review. 


\section{Introduction}

The education system in Poland is customarily based on various forms of education, however, it is mainly based on contact and interaction between the lecturer and the student. Despite the existence of different platforms for non-contact learning, so far in most areas of education, little use has been made of them. On the other hand, in the case of vocational education, which in principle puts the main emphasis on acquiring practical skills, these paths were not used in practice. It should be noted the fact that in the framework of vocational education there is a division on the direction in which education can be successfully based on remote forms of training provide the necessary content, as exemplified by the computer science in the area of programming in the selected language, for example. Python. At the same time, there are areas where contact with the trainer and the equipment is necessary, and the acquisition of the appropriate scope of knowledge is impossible without contact training, e.g. machine tool operator or metrologist. At the turn of 2020/21, the situation changed radically, as education in Poland and around the world faced new challenges related to the growing number of SARS-CoV-2 virus infections, which ultimately led to the declaration of a pandemic. The difficulty in this situation was raised by the dynamics of the entire process, because at the turn of less than a month, the forms of classes had to be radically changed. In the Polish case, more specifically, Silesian University of Technology, the situation was as follows (Iwińska, 2020):

- On March 4, 2020, the first laboratory-confirmed case was found in Poland.

- March 11, 2020 The World Health Organization (WHO) recognized the SARS-CoV-2 epidemic as a pandemic.

- On March 20, 2020, the state of the epidemic in Poland was announced.

- On March 25, 2020, suspension of contact forms of education (full-time classes) at the Silesian University of Technology based on the decision of the Ministry of Science and Higher Education.

This condition applies to the present day, with a few exceptions where for short periods with the consent of individuals supervising attempts to return to the forms of contact with hybrid education, which enabled a reduction in class sizes and the total number of students residing in the college. 


\section{Educational requirements in the context of remote learning}

The result of the situation, the sudden change of educational units from contact to non-contact form of education, was the necessity to develop appropriate ordinances and regulations by managing bodies. In the case of the Silesian University of Technology, a number of Rector's ordinances can be cited, e.g. No. 104/2020 (Monitor Prawny, 2020); No. 200/2020 (Monitor Prawny, 2020), which formalized the rules of conducting classes and verifying the achieved learning outcomes with the use of distance learning methods and techniques. Among the many entries contained in them, attention should be paid to:

- allowing synchronous and asynchronous forms of classes,

"... learning outcomes covered by the study program may be obtained during classes conducted with the use of distance learning methods and techniques ... synchronous and asynchronous interaction between students and teachers ..." (Legal Monitor of the Silesian University of Technology, item 901),

- determining the form of transferring knowledge concerning, in particular, laboratory classes of a practical nature,

"... it is allowed to conduct laboratory classes using the remote education platform used at the University, where the teacher discusses the instructions referring to previous exercises and results obtained by students...

... conducting laboratory classes on methods and techniques of distance learning that enable conducting various kinds of experiments...

... using audio and video recordings showing the course of measurements, simulations, experiments, etc. and providing measurement results via the platform for remote education...

... conducting real-time measurements in the laboratory by the tutor and their presentation using ... a platform for remote education. During the measurements, students prepare a measurement report...

... use of computer equipment, it is recommended to conduct remote classes or use audio and video recordings showing the operation of the program ..." (Legal Monitor of the Silesian University of Technology, item 901),

- determining the form of crediting and verification of obtaining the desired learning outcomes,

"... verification and assessment of learning outcomes achieved during the classes are carried out ... in written or oral form ... it is in the form of ... electronic...

... proceed to pass ... have a device that supports information technology chosen by the teacher, and prepare a room in which he will test ... so that there will not be another person in it, there are not ... multimedia or telecommunication devices ... materials and 
utensils must not be present either auxiliary ..." (Legal Monitor of the Silesian University of Technology, item 901),

- enabling verification of the conditions in which the passing test or exam takes place, ... the person conducting the exam in case of doubts as to the identity of the student ... has the right to verify his / her data ... student ID...

... has the right to verify the conditions of their passing, in particular the room in which the student is staying...

... at the request of the person conducting the test or examination, the student or doctoral student is obliged to provide the screen of his device ..." (Legal Monitor of the Silesian University of Technology, item 901).

In conclusion, the lecturers obtained the necessary tools and clear guidelines regarding the acceptable form of classes, as well as the organization of credits and exams. It should be particularly emphasized here that there are clearly defined requirements, i.e. the obligation to use devices that enable image and sound transmission, which enables full interaction and control of the test or exam being conducted. At the same time not so clear rules formulated in the context of its regular activities, in particular laboratory and in such a situation often interact with the participants of the course was difficult, and the cameras were running only good will on the part of students.

The provisions cited above included the obligation to obtain learning outcomes within individual subjects. And here some problems related to the possibility of obtaining fully selected effects in subjects such as Programming and operation of machines and production systems, due to its practical nature, were revealed. The learning outcomes assigned to operating the devices, as in the case of other subjects, were divided into three groups: knowledge/skills/competences.

The group of skills constituted the biggest problems or doubts in the context of the possibility of obtaining the full educational result. Examples of skills closely related to the practical side of service, i.e .:

After completing the course (lecture, laboratory exercises), students should:

- have knowledge of available CNC programming techniques,

- have detailed knowledge of the use of machines used during laboratory classes and techniques of preparing numerical programs for these machines,

- be able to practically develop technological documentation for the implementation of tasks,

- analyze a technological problem, develop an NC program,

- arm the machine, simulate and start the NC program,

- be able to organize the work of several people during the implementation of tasks,

- be able to prepare a team final report on a laboratory exercise. 
Mastering the theoretical principles in the context of the above-mentioned skills that students are to acquire as a result of participating in the course does not seem to be sufficient. Even a perfect knowledge of the theoretical foundations regarding the principles of operating machines or CNC controllers will not ensure the correctness of actions using it. In this case, the lack of access to actual production equipment makes it impossible to fully verify the effects of the decisions made.

\section{Virtual models limitations}

Let's analyze the available tools for the implementation of laboratory classes within the course, e.g. operation and programming of CNC machines. There are both standalone software products as well as simulation software for industrial controllers. Since in non-pandemic conditions we have real machines available, solutions based on simulators dedicated to these machines seem to be appropriate. The basic tool in this case is the simulation environment, consisting of an interactive text editor and a graphical visualizer of tool paths (Figure 1).

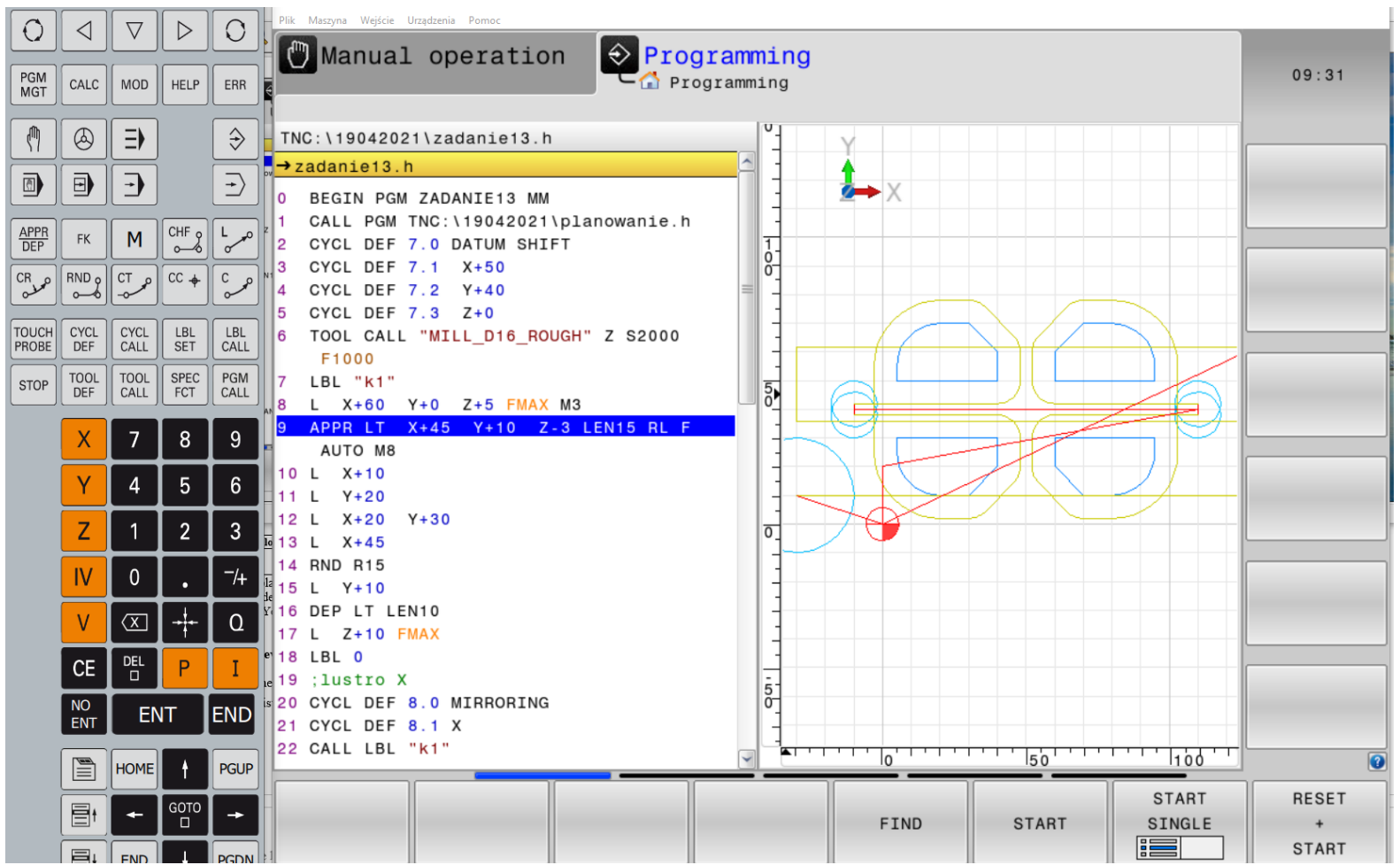

Figure 1. Interactive editor with graphical visualization. 
In this case, the student carrying out programming tasks can observe the effects of the decisions made and the program instructions used. This solution allows you to learn syntax of the language used, the methodology of entering coordinates, cutting parameters, etc. The 2D visualization of the paths themselves is not sufficient to evaluate the all required effects. Therefore, another tool in this type of software is 3D visualization of simulation, in which the workpiece and tools are visible. The workpiece is shaped during the operation of the individual cutting tools. In many cases, at this stage, it is possible to evaluate the obtained effects as a result of a color map and workpiece measurement. This case is shown in Figure 2. The color of the area makes it easier to identify the tool that was working there. When working with multiaxis machines, the limitation is the fixed position of the workpiece. In such a machine, the workpiece can rotate, and the tool axis does not change, unlike in the simulator.

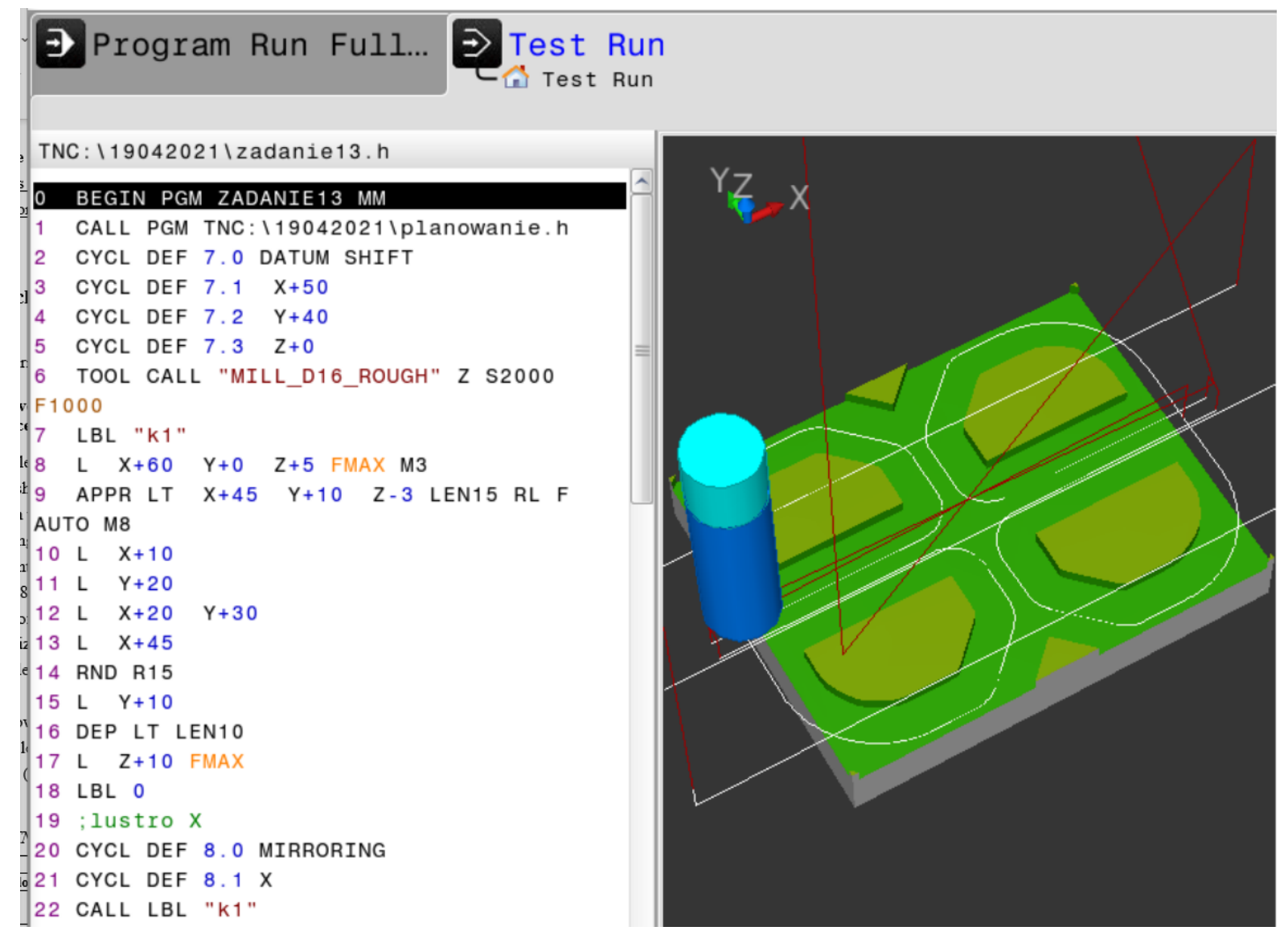

Figure 2. Example of 3D model workpiece simulation with toolpaths. 
The next step is to use the virtual machine model (Figure 3). In this case, the process takes into account the kinematics of the machine model. In this way, the mismatch that occurred in a typical simulator is eliminated. In this case, we get complete access to the real CNC controller software, including all its settings. The software operator can describe all important parameters and simulate the process as in a real machine. All machine operations are simulated by a 3D model of the machine with a visible working space. Additionally, in this case, the software can control the collisions of machine units. Both a virtual and real control panel can be used to operate the machine. Such a panel contains switches and keys that are located on the desktop of real machines. Such software brings the student closer to the operation of the real machine, because it has to perform basic maintenance activities, but still the relationship with the real machine requires appropriate imagination. In this form, simulation software seems to be sufficient for learning programming, but only partially meets the requirements for operating real machines.

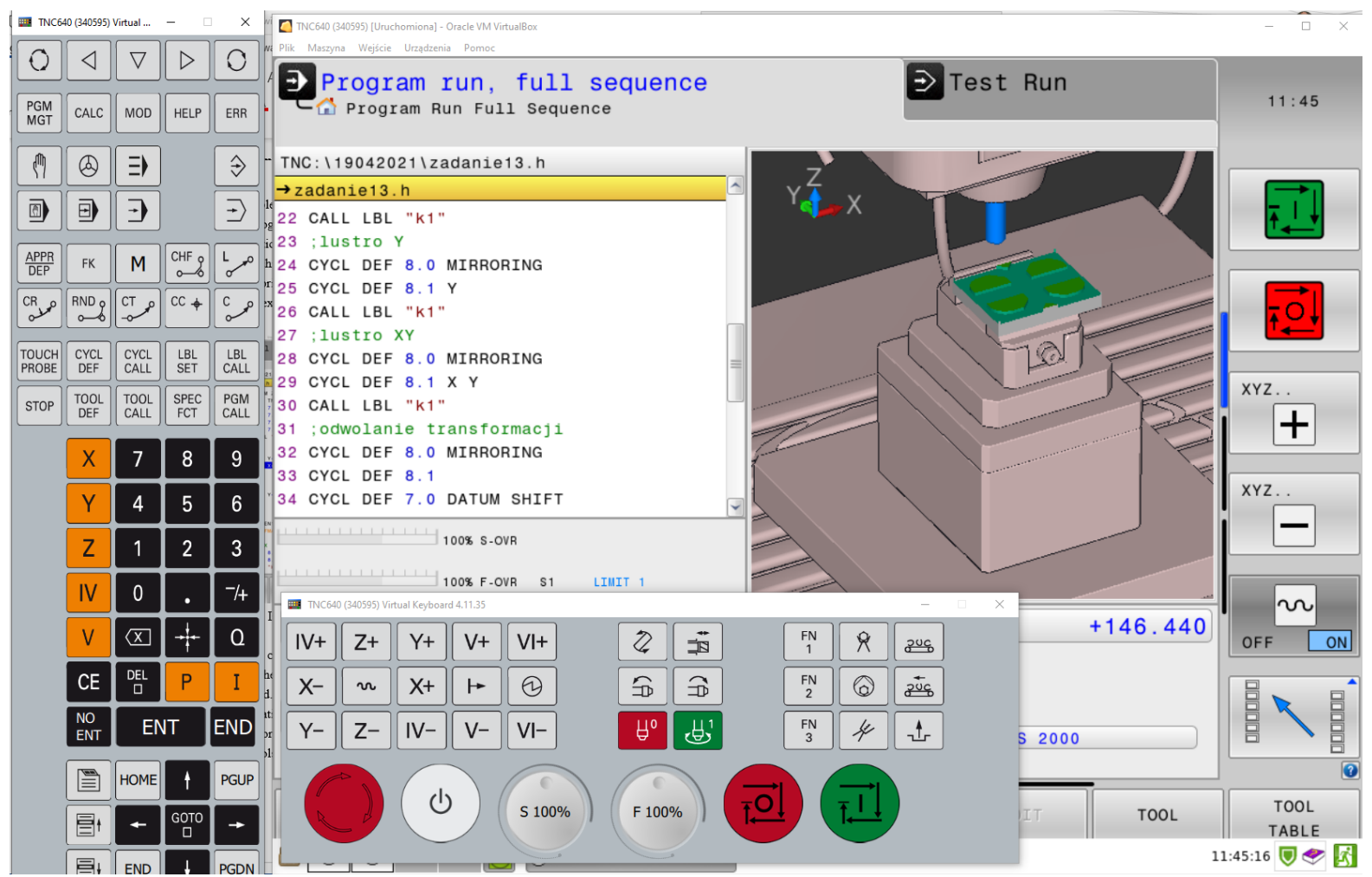

Figure 3. Screen view of virtual machine simulator with complete virtual keyboard. 


\section{Industrial twins as teaching device}

The industrial twin, also known as the digital twin, is an important solution used in Industry 4.0. Thanks to it, it is possible to combine the virtual world and reality, which gives you huge and completely new opportunities. A digital twin is a digital replica, a mathematical model of a given object / product, process, systems or service. It derives from the concept of the virtual equivalent of the physical world, which was created at the beginning of this century at the University of Michigan. The very idea of creating virtual models of devices was introduced by NASA. The space agency created replicas of space capsules and installed hardware and software in them, and in this way was able to test them. With time, when appropriate possibilities and tools appeared, physical models began to be transferred to virtual reality.

The digital twin model consists of: a physical object, digital representation, and linking them through real-time data exchange and processing to continuously update the mapping. Due to the advancement of technology, the collection of data and its transmission is no longer done manually as well as offline and in real time.

The existing infrastructure and software were used to build the teaching device. In the laboratory of Technopark Gliwice there is an advanced multi-task machining center by OKUMA (Figure 4) The MULTUS B200II machine is equipped with the OSP-P300S control by OKUMA. It is an advanced control system, well integrated with the machine, offering many special functions. The CAS (Collision Avoidance System) is an extremely important part of the software. It uses a virtual machine that allows for complete mapping of the actual content of the workspace, including clamping devices, tools, workpiece, measuring instruments, etc. During direct classes, students can perform all maintenance activities on this machine. In particular, activities related to the launch of previously prepared programs. For this purpose, they must equip the machine with tools and equipment, modeling and position all elements of the machine's working space. In such a case, the implementation of numerical programs requires them to be run in compliance with all safety rules. During the implementation, it is sometimes necessary to return the machine from collision positions, restart programs from different places, and change settings. All these task are supervised by the CAS system, which allows for collision-free operation. Since the CAS system settings are critical, they are directly controlled by the supervising teacher. After approving the critical settings, the students themselves cannot change them in further work. 


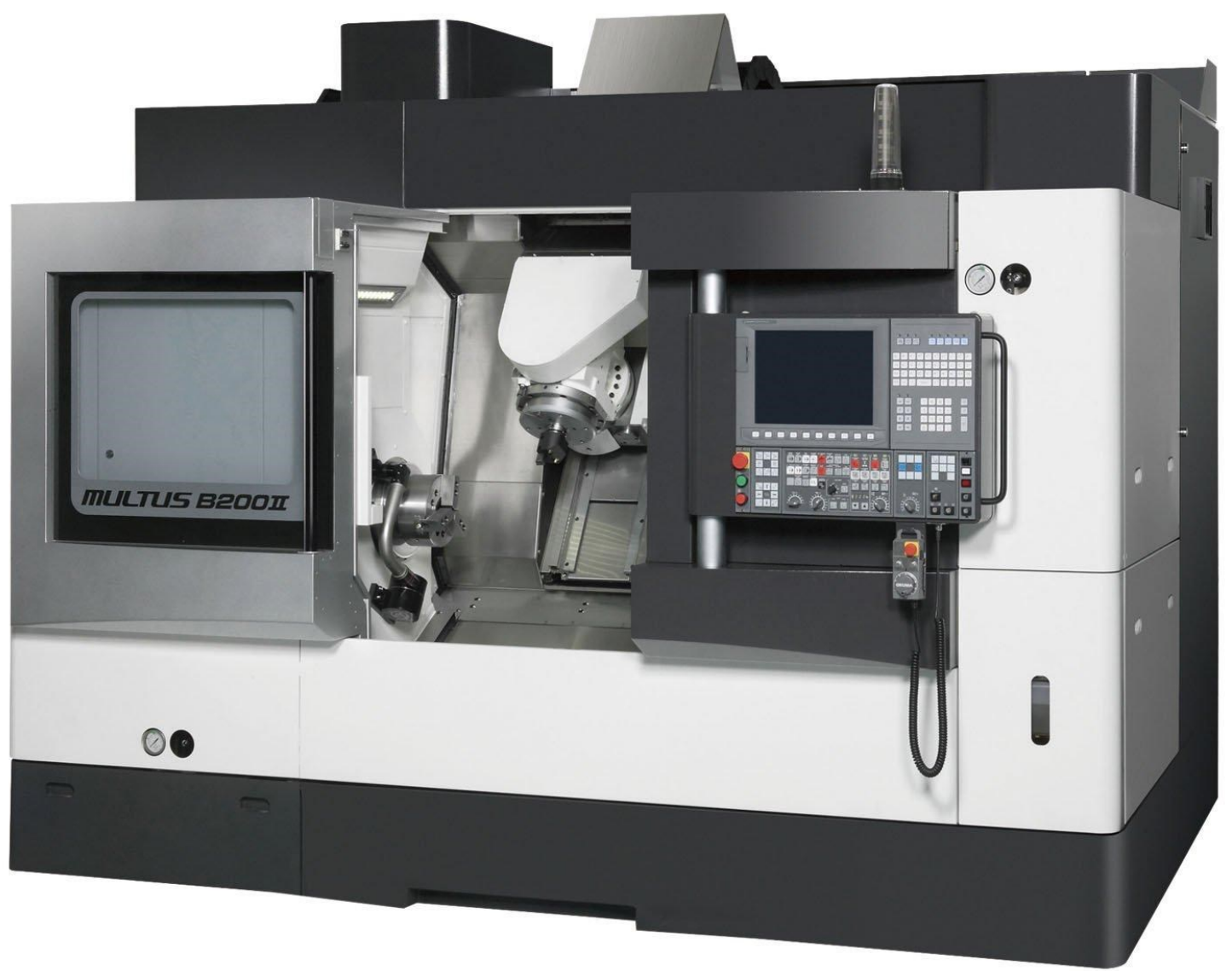

Figure 4. Multitasking machining center OKUMA MULTUS B200II at Technopark Gliwice.

On a remote station, it is possible to run a twin software in the form of a virtual OSP-P300S control simulator (Figure 5), which enables virtual execution of all activities performed on a real machine. It is an environment that allows both programming and testing of programs, which can then be transferred to the MULTUS B200 machine. As a rule, this software works separately from the machine. When the simulation computer and machines are connected to the network it is possible to transfer files between them.

In order to achieve the desired educational results, access to both the machine tool and the software is necessary. This is usually done in separate classes. Work with the simulator takes place on individual computer stations, which enables individual problem solving. Access to the simulator is also possible outside the classroom on the student's own computers when they can perform homework.

Access to the machine tool is limited to workshop activities. Group access to the machine is not effective. Usually, the most active students perform direct maintenance activities, while the rest are only passive observers. It is also influenced by the limited possibility of observation resulting from the space available around the machine. As a result, in terms of the requirement to operate machinery and equipment, achieving the desired educational effect is difficult. It seems necessary to increase the number of hours of access to the machines. 

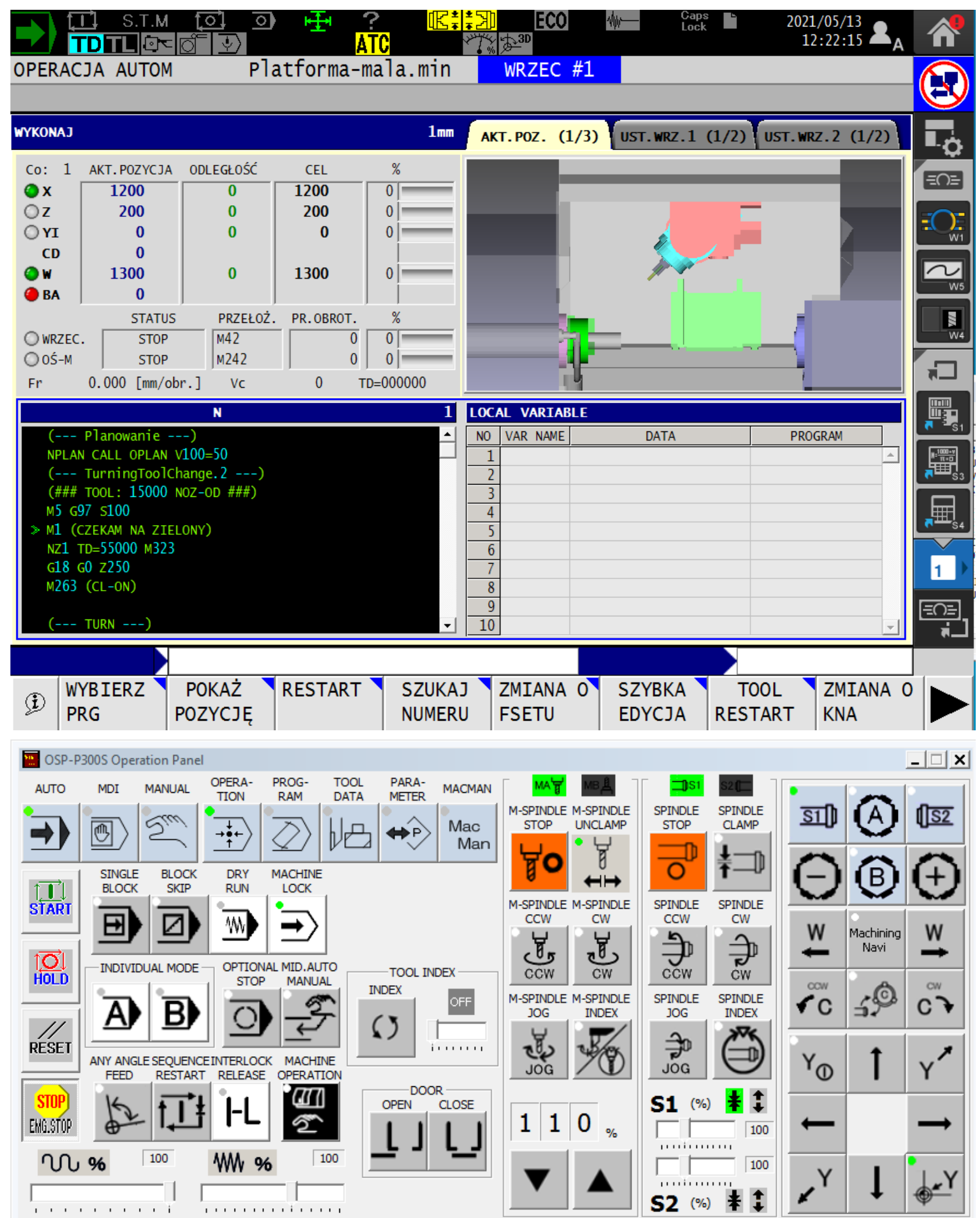

Figure 5. Okuma OSP-Visualisation software with complet virtual controll keyboard.

Due to the lack of direct access to the machine, an attempt was made to use the digital twins technique. For this purpose, special communication software was developed based on the technology OPC UA as data transmission protocols. Okuma's controls allow programmer to use the API to build own applications. This allows to develop software that runs directly on the controller. The software can access the current machine settings, and also allows to change 
these settings. It is possible to read, for example, the current position of the machine's mechanisms, cutting parameters such as rotational speed, the amount of working feed, information about the tools used, the states of auxiliary systems and other inputs and outputs.

Figure 6 shows a schematic presentation of the group work during distance learning. The trainer has direct access to the machine tool, where he can make critical settings and take maintenance actions when necessary. It was assumed that he could perform standard educational tasks in parallel with the use of a camera and a microphone. The video image is transmitted to students in real time, both from a blackboard and from the machine's working space. At the same time, students have access to the desktop and digital screen of the machine tool twin. As can be seen in Figure 5, the current operating states of the machine tool are displayed on the top bar of the screen in the form of pictograms that change color depending on the activity. The virtual keyboard is equipped with keys with control LEDs, which allows students to easily identify their status. The programs prepared by the students are sent to the machine control. The machine must be prepared for work, i.e. the workpiece is placed in the holder, appropriate tools are put in the magazine. These activities must be performed directly in the workshop. They are performed by a designated person or trainer. The remaining activities are performed remotely by students under the supervision of a trainer. The trainer selects a person from the group of students who has the operator status. The selected person has the ability to manipulate a digital twin. The other participants can observe the current status of the machine tool on individually personalized screens. The exchange of information between users can be done either by voice or via chat.
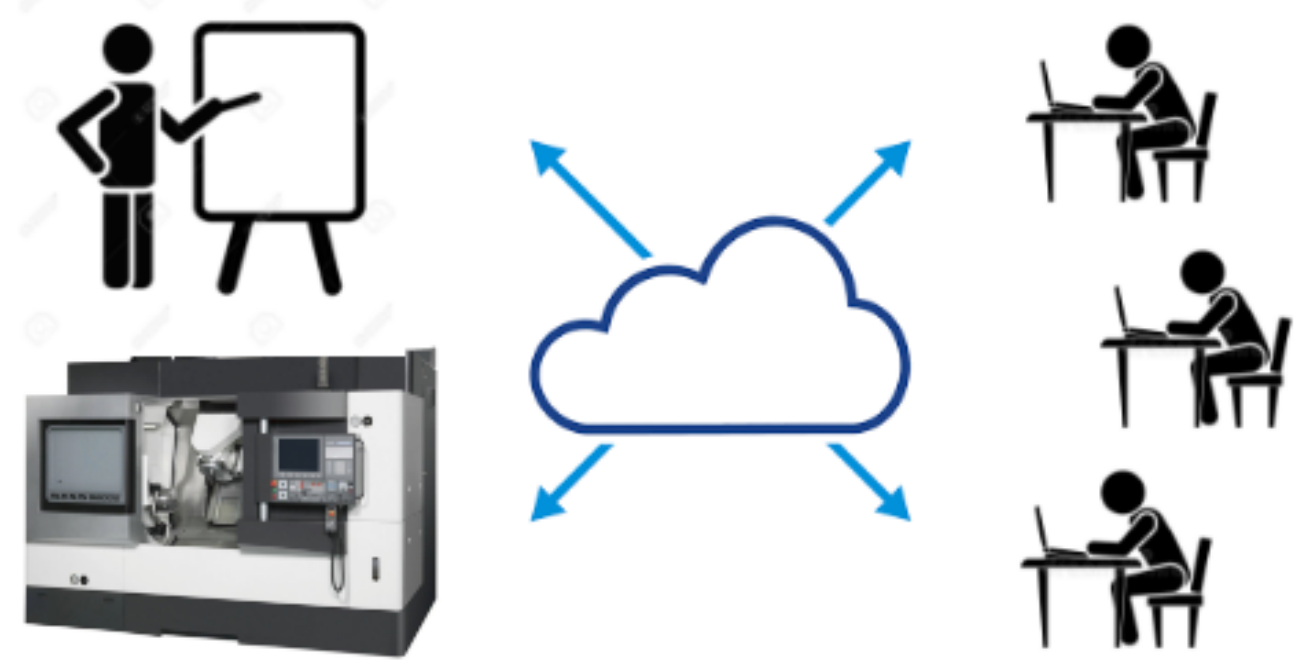

Figure 6. Cloud based learning with digital twin of machine tool. 
This form of group collaboration has been tested and has demonstrated the limitations of remote control tasks. In the first place, the problem was the inability to remotely control the start/stop button. Okuma OSP control in terms of simulation is based on the machine lock mode. The activation of this mode causes the complete blocking of the working systems, but CNC controller, together with the virtual machine, works normally. To start automatic operation (even for simulation) it is necessary to press the cycle start button. For security reasons, the API library does not provide direct access to handle this button. In this case, the remote operator can perform all settings, activate most of the keys responsible for displayed screens and basic functions, but cannot execute commands in automatic mode. As a result, the trainer has to do the pressing of the start button. The same problem applies to pausing the machine tool with the feed hold button. For safety reasons, the biggest problem may be the inability to quickly press the Emergency Stop button.

A suggested method of solving the problem of accessing the functions of special keys is to develop a special adapter that interacts with the machine. A design of a special adapter for communication with the machine and external system has been proposed. This adapter is a software and hardware solution based on a microcomputer, eg Nvidia Jetson Xavier NX, which is designed to enable the implementation of tasks requiring operation at the level of electrical signals. It is necessary, for example, for the implementation of tasks related to the operation of critical functions such as automatic cycle start, feed hold, and emergency stop. This adapter will work connected directly to the machine control, but it will be operated with virtual keys implemented in a digital twin available in the cloud. Thus, it will be possible for the remote operator to run programs and perform other tasks in automatic mode. At the same time, persons supervising the process carried out by the machine will have access to the emergency stop button.

The proposed agent, as a separate computer, could also take over additional tasks related to the teaching process. It is possible to equip it with additional cameras, sensors, etc. Probably new applications and needs will arise in the course of further development.

\section{Summary}

The remote work mode forced by the pandemic may contribute to faster implementation of IT technologies, which will soon become standard solutions in industry 4.0. The proposed methodology of the teaching process with the use of a digital twin allows to combine the potential of software simulators and real workshop equipment. On the one hand, it cannot replace completely direct contact with laboratory equipment, on the other hand, in the case of group work, it gives more individual access to it at the same time for many people. 


\section{References}

1. Biesinger, F., Weyrich, M. (2019). The Facets of Digital Twins in Production and the Automotive Industry. 23rd International Conference on Mechatronics Technology (ICMT) IEEE, Salerno, Italy.

2. Iwińska, M. (2020). Wyzwania edukacyjne podczas pandemii w opinii studentów pracy socjalnej. Biblioteka Instytutu Spraw Społecznych 13 Uniwersytetu Pedagogicznego im. Komisji Edukacji Narodowej w Krakowie, p. 135. Retrieved from https://iss.up.krakow.p1/ wp-content/uploads/sites/13/2021/01/biss_13_e-book.pdf, 03.04.2021.

3. Koludo, A. (2020). Strategie kształcenia na odległość. In: J. Pyżalski (ed.), Edukacja w czasach pandemii wirusa COVID-19. Z dystansem o tym, co robimy obecnie jako nauczyciele (pp. 43-50). Warszawa: EduAkcja.

4. Stark, R., Fresemann, C., Lindow, K. (2019). Development and operation of Digital Twins for technical systems and services. CIRP Annals - Manufacturing Technology.

5. Umedaa, Y., Otab, J., Kojimac, F., Saitoc, M., Matsuzawac, H., Sukekawac, T., Takeuchib, A., Makidaa, K., Shirafujib, S. (2019). Development of an education program for digital manufacturing system engineers based on 'Digital Triplet' concept. Retrieved from http://www.elsevier.com, 10.05.2021.

6. Zacher, S. (2020). Digital Twins for Education and Study of Engineering Sciences. International Conference on Life Sciences, Engineering and Technology. Retrieved from http://academia.edu, 10.05.2021. 